\title{
DÍALOGO DE SABERES PARA UNA REFORMA DEL PENSAMIENTO Y LA ENSEÑANZA EN AMÉRICA LATINA: MORIN, POTTER, FREIRE Carlos Delgado*
}

RESUMEN: La reforma del pensamiento y la enseñanza ha sido reconocida como una necesidad en la búsqueda de salidas a la crisis de la humanidad. Una reforma de esta magnitud reta los paradigmas establecidos en la ciencia, los modos de vivir y las estructuras organizativas que participan -y muchas veces gobiernan-el proceso de realización de la vida social. Tres líneas de pensamiento, relativamente aisladas entre sí -el pensamiento complejo, la bioética global y la pedagogía del oprimido-, tienen una gran influencia en Latinoamérica, y configuran redes de transformación práctica de gran impacto. En el texto se exploran los fundamentos epistémicos comunes entre las propuestas y se muestran las potencialidades que ofrecen para una reforma del pensamiento y la enseñanza.

$$
\text { sode }
$$

ABSTRACT: Reforming ways of thinking and teaching have been recognized as a necessary measure in the search for solutions to the social crisis. Such reforms challenge established paradigms in science, ways of living, and organizational structures which participate and often rule social life processes. Three distinct lines of thought, namely complex thinking, global bioethics, and pedagogy of the oppressed, have been influential in Latin America and have established significant networks of practical change. In this article, we will explore their common fundamental epistemic basis and their potential in reforming thought and teaching.

PAlabras ClaVE: pensamiento, educación, enseñanza, Morin, Potter, Freire.

KEYWORDS: thought, education, teaching, Morin, Potter, Freire.

RECEPCIÓN: 11 de enero de 2010.

APROBACIÓN: $1^{\circ}$ de febrero de 2010.

* Universidad de la Habana. Consejo Académico Internacional de Multiversidad Mundo Real Edgar Morin. 
CITAM Derechos Reservados.

La reproducción total o parcial de este artículo se podrá hacer si el ITAM otorga la autorización previamente por escrito. 


\section{DÍALOGO DE SABERES PARA UNA REFORMA DEL PENSAMIENTO Y LA ENSEÑANZA EN AMÉRICA LATINA: MORIN, POTTER, FREIRE}

\section{P ara cumplir el objetivo fundamen-} tal de formar para la vida, la educación contemporánea debe mantener un elevado nivel de actualización con respecto a los avances científicos y tecnológicos. Sin embargo, dos tendencias reduccionistas lo obstaculizan. Por una parte, el cientificismo tecnicista se limita a la enseñanza de las materias científicas y tecnológicas, y la divorcia de la enseñanza de las humanidades y del análisis de los imprescindibles aspectos y problemas humanísticos que acompañan los avances científicos y tecnológicos. Por otra, el mercantilismo alimenta la tendencia a liberar los curricula de los aspectos científicos más importantes y novedosos, para reducir la enseñanza a los mínimos que garanticen la formación de operarios diestros en acciones segmentadas. En oposición a estas tendencias, Edgar Morin, Van Rensselaer Potter y Paulo Freire coinciden en plantear la necesidad de un cambio fundamental en nuestros modos de manejar el conocimiento, y demandan para ello una transformación profunda de la educación, la enseñanza y el pensamiento.

Morin ha planteado con claridad y agudeza la necesidad de una reforma simultánea del pensamiento y la enseñanza, que tenga en su centro la condición humana y nos habilite para encontrar soluciones a los problemas fundamentales que enfrenta la humanidad. Potter ha resaltado la importancia de enfrentar los desafíos de la supervivencia humana mediante un replanteamiento de la responsabilidad individual 
y social, y con ello ha desarrollado una propuesta bioética-política que conduce a una educación nueva. Simultáneamente, Freire centró la atención en la necesidad de un cambio educativo que reconozca las relaciones de dominación y se proponga superarlas. Morin, Potter y Freire coinciden en plantearnos la necesidad de un cambio educativo, y acentúan la importancia del lado ético-político de esa transformación hacia una antropoética (Morin), una educación bioética-política comprometida con el futuro (Potter), y una educación política de la autonomía liberadora (Freire).

La notable influencia que tienen estos autores en diversos círculos académicos latinoamericanos y mundiales podría bastar para intentar tomarlos juntos al pensar la reforma educativa. Esta necesidad se hace más evidente si consideramos, además, que la segmentación de pensamiento, actividades y círculos intelectuales condiciona muchas veces que, quienes han estudiado la obra de uno de ellos, desconozcan la obra del resto y pasen así por alto sus coincidencias fundamentales.

No obstante lo anterior, para tomarlos juntos no bastan la necesidad sentida y la fragmentación reconocida. Existen fundamentos epistémicos que hacen ineludible tomarlos juntos para intentar una reforma educativa en Latinoamérica. Para comprenderlos necesitamos una hipótesis que ofrezca un marco integrador de los cambios en el saber humano y la urgencia de una transformación que considere las propuestas que nos ofrece el círculo creativo que conforman Morin, Potter y Freire.

\section{Una hipótesis para explicar los cambios en el saber humano}

Desde la segunda mitad del siglo XX, la revolución científico-técnica (RCT) ha marcado el devenir de la humanidad, dotando la vida cotidiana, la industria y la actividad científica de nuevos métodos, informaciones y artefactos. Los medios de comunicación se hacen eco de estos cambios, y tanto los productos materiales de esa revolución, como las reflexiones que motiva, han pasado a ser de amplio dominio público. Sin embargo, permanecen en la sombra, tanto para la comunidad académica como para los medios de comunicación y el amplio público, los cambios fundamen- 
tales en el saber humano que acompañan esa revolución y que constituyen, en sí mismos, otra formidable revolución, paradójicamente todavía inadvertida. Afirmamos entonces que al lado de la revolución reconocida -la RCT-, se desenvuelve otra, inadvertida, subyacente, oculta tras los cambios perceptibles: la revolución en el ser humano, en los modos de concebir y producir el conocimiento y la ciencia misma. Se trata de una revolución que está cambiando nuestra comprensión del sentido y alcance del conocimiento y su relación con los valores humanos; las relaciones entre ciencia y moral, subjetividad y objetividad en el saber. Esta revolución modifica sustancialmente el lugar del conocimiento científico en el sistema del saber humano y su consecuencia más profunda es la elaboración de un nuevo saber que rompe con el ideal clásico de racionalidad.

Por su carácter cultural, la revolución científica y tecnológica, que incluye los científicos, los artefactos y las tecnologías con que se pertrecha la vida social y se transforma la naturaleza, afecta también sustancialmente al hombre común y la vida cotidiana. Han tenido lugar amplios procesos de subversión material y espiritual de la cotidianeidad, y una consecuencia directa de ello ha sido la activación cognitiva y práctica del hombre común, lo que implica que los cambios en el saber, los modos de conocer, el valor del conocimiento y su vinculación con las formas de vida, ${ }^{1}$ no son exclusivamente cambios de naturaleza teórica, o que pertenecen al dominio de la teoría y la actividad intelectual de un sector de la humanidad. Se trata de cambios que tienen un rostro material concreto en los artefactos y tecnologías, y en la modificación de las bases materiales y espirituales del desenvolvimiento cotidiano de las personas. Cambia la vida cotidiana y es un factor fundamental a considerar, pues no se trata entonces de un proceso circunscrito a uno o varios sectores, sino que afecta a la humanidad en su conjunto, indepen-

${ }^{1}$ A diferencia de épocas anteriores donde la vida cotidiana se desenvolvía dentro de patrones cerrados de interconexión, hoy la vida cotidiana se caracteriza por la preferencia por el cambio, la elevación del valor social de la novedad y la creatividad, así como la instrumentación práctica del conocimiento científico en la vida cotidiana, lo que deviene en amenaza para la vida. Véase una fundamentación más amplia en Carlos Delgado, Hacia un nuevo saber. La bioética en la revolución contemporánea del saber, 2007, La Habana, Ediciones Acuario, Centro Félix Varela, p. 13-24. 
dientemente de que los cambios no signifiquen, automáticamente, beneficio o modificaciones que pudieran catalogarse exclusivamente como positivas.

Entre las teorías de ruptura que pueden ubicarse como detonantes de la revolución contemporánea del saber, se encuentran el holismo ambiental -que hunde sus raíces en el pensamiento de Aldo Leopold y la ética ambiental, Arné Naess y la ecología profunda-, la epistemología de segundo orden -que desde Von Foerster reconsidera y replantea el problema de las bases del conocer humano, las nociones de sujeto y conocimiento-, la bioética de Potter - que revoluciona el terreno de la ética con varias ideas novedosas-, y los estudios de la complejidad, dentro de los cuales la obra de Edgar Morin tiene rostro propio como propuesta integradora.

Estos cuatro desarrollos teóricos tienen una importancia crucial, en sí mismos y en su vínculo con la vida cotidiana. El holismo ambiental y la bioética están directamente vinculados a las problemáticas y preocupaciones del hombre común. Podría afirmarse que en ellas se verifica una transición de la práctica del saber a la teoría del saber, pues lo que emana de novedoso en las reflexiones tiene en su base preocupaciones ciudadanas y problemas prácticos que afectan y son sentidos más allá de los círculos intelectuales, ocupados en asuntos de teoría científica, política o ética. Por su parte, la epistemología de segundo orden y los estudios de complejidad tienen su origen en preocupaciones vinculadas a la ciencia y la elaboración de nuevas teorías; se trata de un movimiento inverso, que va de la teoría del saber y sus preocupaciones, a la práctica del saber, pues sus elaboraciones se plasman también y contribuyen a dar respuesta a preocupaciones humanas generales. No es extraño, por tanto, que las cuestiones cognoscitivas, éticas y políticas, aflorasen de manera desigual, pero constante, en estas cuatro líneas de desarrollo teórico: en la bioética y el ambientalismo emergen en un primer plano, protagónico y rector; mientras que en la epistemología y los estudios de la complejidad, lo hacen de manera derivada, en un segundo plano, como consecuencia del trabajo en problemas básicos del conocimiento humano. 
Esta circunstancia no debería confundirnos, pues hablar de primeros o segundos planos indica únicamente la preocupación de origen, a partir de la cual se desarrollan las reflexiones, pues estos desarrollos conceptuales se caracterizan precisamente por intentar la reintegración del conocimiento y la valoración, el saber científico y la moralidad humana. En eso consiste precisamente la revolución del saber: en la ruptura con viejos ideales, normas y valores signados por la separación y la contraposición de lo cognitivo y lo valorativo. La revolución inadvertida vendría a ser, entonces, proceso de formación de nuevos ideales de conocimiento y un saber distinto.

Entre los elementos básicos del saber nuevo se encuentran el reconocimiento de la necesidad de un diálogo entre científicos y no científicos; entre el saber científico y otros saberes; la urgencia del cambio en el objeto de la ciencia, que no es concebido ya como el estudio del mundo exterior, sino el estudio de éste y de las consecuencias prácticas del conocimiento obtenido; $y$, finalmente, la urgencia de un nuevo diálogo con la naturaleza, que reconozca que no es el humano el único ser creativo, sino que la naturaleza tiene creatividad; una creatividad que no ha sido tomada en cuenta por la ciencia anterior.

La bioética, el estudio desde la epistemología, la complejidad y el holismo ambientalista han planteado la necesidad de una ética de la vida y un cambio en el objeto de la ciencia; la urgencia de una nueva mirada a la cognición; el problema del mundo en el conocimiento; la objetividad y la subjetividad; el determinismo, la certeza científica y el control; se han planteado la creatividad de la naturaleza como problema científico, que es cuestionarse la incertidumbre, la certidumbre y la causalidad como parte de las bases teóricas de la preocupación ética sobre la ciencia contemporánea y sus productos; han propuesto un concepto nuevo de naturaleza y un cambio en nuestra actitud espiritual y material respecto a ella; han indagado en las bases prácticas de las preocupaciones éticas con respecto a la ciencia.

Uno de los elementos integradores que delimita y configura el nuevo saber está relacionado con el reconocimiento del carácter interno de lo valorativo y lo moral en el conocimiento científico. Esta idea no es, ni mucho menos, reconocida por todos, debido fundamentalmente al peso de 
la ciencia clásica, la dicotomía del conocimiento y la moral -el mundo de la naturaleza "autómata" causal y el hombre "libre" moral-, que sigue ejerciendo una influencia abrumadora para la mayoría de las personas.

La reforma educativa profunda es parte de la revolución contemporánea del saber, y ha de beber en aquellas fuentes que aportan al nuevo saber humano. Es precisamente esa coincidencia fundamental entre Morin, Potter y Freire, como portadores de un nuevo saber, la que hace sus ideas cercanas e ineludibles al plantearnos una reforma profunda de la enseñanza. La reforma ha de beber constantemente en el nuevo saber humano y su resultado no puede ser otro que la extensión y ampliación de ese nuevo saber.

\title{
Reforma del pensamiento y crisis de la humanidad
}

\author{
Conocer lo humano no es sustraerlo \\ del Universo sino situarlo en él. \\ Todo conocimiento [...] debe contextualizar \\ su objeto para ser pertinente. ¿Quiénes somos \\ nosotros? es inseparable de un ¿dónde estamos?, \\ ¿de dónde venimos?, ¿a dónde vamos? \\ E. Morin, La cabeza bien puesta.
}

La contextualización del conocimiento es -como señala Edgar Morin-, un atributo fundamental que configura su pertinencia. Ubicados en el mundo contemporáneo y en latitudes latinoamericanas, es imprescindible que coloquemos el tema de la educación y su reforma en una cuádruple contextualización, que incluya el mundo de hoy en sentido general, y el contexto inmediato latinoamericano, los avances científicos y los problemas cognoscitivos que lo configuran. Para hacer posible la reforma necesitamos una contextualización a la vez epistémica, ética, política y pedagógica.

La problemática educativa está indisolublemente unida a las del poder, la inclusión y la exclusión social. Es imposible pensar la educación haciendo abstracción de los vínculos de determinación que enlazan 
educación y poder, dominación, exclusión y reproducción social, puesto que la educación de una época y una sociedad dadas tienen la misión social de reproducir el tipo de relaciones sociales dominantes y los tipos humanos que hacen posible el mantenimiento de esa relaciones.

De esta manera, habría que señalar, en primer lugar, que los problemas principales de la educación no son metodológicos o pedagógicos, sino éticos y políticos. Involucran la toma de decisiones políticas que permitan conjugar pacíficamente, como señalara Carlos Fuentes, ${ }^{2}$ las exigencias del cambio y la tradición; la participación de la escuela, la familia y el maestro desde la base; la atención a los procesos de cambio rápido y global. Y también aquellos problemas que bioeticistas de la talla de Volnei Garrafa han calificado como “problemas persistentes": la exclusión social y la concentración del poder, la pobreza, la miseria y la marginalización. ${ }^{3}$ La situación latinoamericana, a pesar de las diferencias entre países y entre regiones dentro de un país, nos muestra una combinación enmarañada de estos contextos que se superponen y se mezclan.

En los extremos quedarían la pérdida total de la identidad mediante la sumisión a los procesos globales, o la supuesta salvación de la autenticidad mediante el aislamiento con respecto a ellos. Ninguno de estos extremos puede conducir a un futuro viable, lo que nos replantea la importancia crucial de la reforma educativa. Aunque ella por sí sola no puede resolver el problema, si podría sentar las bases para un cambio fundamental que permita la salida de la región a nuevos horizontes de inserción social y sobrevivencia.

La reforma educativa debe plantearse con claridad el desafío de la globalidad. Este desafío no consiste en mirar únicamente la globalización política y económica. Significa atender: 1) la tensión permanente entre la estandarización y la diversidad (biológica, cultural, sociopolítica); 2) la tensión entre los procesos de ampliación del conocimiento (caracterizados en la actualidad por su profundidad, intensidad y extensión) y su manejo: lo que se plasma en las problemáticas de la incertidumbre del conocimiento, y del conocimiento "no manejable";

${ }^{2}$ Véase Carlos Fuentes, "Por un progreso incluyente", 1997.

${ }^{3}$ Véase Volnei Garrafa y Dora Porto, "Bioética, poder e injusticia: por una ética de intervención”, en José Acosta, Bioética para la sustentabilidad, 2002, La Habana, Publicaciones Acuario, Centro Félix Varela. 
3) el carácter planetario del proceso productivo, de la existencia contemporánea de la humanidad, de los problemas que enfrentamos y de las responsabilidades que debemos asumir como especie; y, 4) la problemática ética de una manera nueva, pues demanda la ampliación del círculo de la moralidad para dar espacio a la naturaleza en ella.

El desafío de la globalidad pone en tensión nuestros conocimientos y nuestra comprensión de las relaciones con la naturaleza y entre las culturas; tensa nuestra comprensión de la responsabilidad. Por eso, para atender a este formidable desafío necesitamos reconsiderar:

1. El valor de la diferencia y la diversidad humanas.

2. El lugar de la responsabilidad individual y del individuo en la construcción de las relaciones sociales.

3. El legado de autores fundamentales como Morin, Potter y Freire.

Enfrentar el desafío de la globalidad significa atender lo que es propio y local, sin descuidar los procesos globales. Necesitamos para ello un planteamiento teórico que permita la comprensión del momento actual que vive la humanidad. En este sentido, la propuesta de Morin para una reforma profunda del pensamiento y la enseñanza es insustituible.

A diferencia de las reformas que se han promovido desde finales del siglo XX en diversos países, ${ }^{4}$ la propuesta de Morin, acogida por la UNESCO y divulgada en obras como Los siete saberes necesarios para la educación del futuro, La cabeza bien puesta, y Educar en la era planetaria, ${ }^{5}$ propone una reforma profunda, simultánea y concurrente, de la enseñanza y el pensamiento. Tiene su base teórica más profunda en la perspectiva filosófica y metodológica que ofrece el pensamiento complejo, y se expresa como una concepción transdisciplinaria, holista y comprehensiva que enfrenta el desafío de la globalidad. La reforma se propone como parte de la búsqueda de soluciones a los grandes problemas que la humanidad enfrenta en la actualidad. Es una propuesta que

\footnotetext{
${ }^{4}$ Para una caracterización véase del autor el artículo "Latinoamérica: reforma educativa y umbrales de futuro", en el libro de Rubén Reynaga (comp.), Homenaje al amigo Edgar Morin, 85 años, México, 2007, Hermosillo, Multiversidad Mundo Real Edgar Morin.

${ }^{5}$ Las dos primeras corresponden a la autoría de E. Morin, mientras que la tercera fue realizada en coautoría con Raúl Domingo Motta y Emilio Roger Ciurana.
} 
coloca en el centro de atención los desafíos de la etapa actual del proceso de planetarización de la humanidad.

Morin ha mostrado que el estrechamiento de vínculos entre regiones distantes del planeta ha dado lugar -a pesar de la exclusión, la discriminación y la dominación hegemónicas-, a una sociedad planetaria en proceso de constitución. Y es esa constitución, en medio de inconmensurables contradicciones, la que genera desafíos enormes. Morin constata la historicidad de este proceso de devenir planetario de la humanidad, la existencia de macroprocesos planetarios y avances tecnológicos que propician la emergencia de una sociedad global. Y simultáneamente, la falta de preparación de los seres humanos para dar cuenta y vivir en el contexto de esas nuevas realidades. Así, lo que se encuentra en el horizonte es el fracaso o el éxito de la humanidad en su conjunto, y la reforma debería coadyuvar a un cambio fundamental que nos permitiera atender grandes problemas-urgencias, entre los que se encuentran:

1) La urgencia epistemológica, que nos convoca a encontrar solución a grandes problemas del conocimiento humano; dar cuenta de los errores; aprender a manejar la incertidumbre del conocimiento; hacerlo pertinente en su contextualización; avanzar por los caminos de la complejidad y la transdisciplinariedad.

2) La urgencia fenoménica ante el desmembramiento social, la heterogeneidad, la exclusión social y la discriminación que acompañan el proceso de acercamiento y homogeneización planetaria.

3) La urgencia individual, que nos exige dar cuenta de las necesidades de los sujetos diversos, involucrados en un proceso de individuación contextualizada a nivel planetario.

4) La urgencia social de poner límites a la planetarización devoradora, enmarcada en los procesos dominantes en las relaciones económicas, políticas y de dominación cultural y natural del capitalismo contemporáneo.

En breve síntesis, nos encontramos en un momento crucial en el que se han configurado las premisas materiales y de comunicación para la existencia de una sociedad mundo, pero donde no existen las 
condiciones que permitan una gobernanza planetaria. El peligro de dictadura global y destrucción (por la guerra o la catástrofe ecológica) es tanto o más grande que antes, y sólo un cambio profundo en las mentalidades, que permita cambios en las acciones y los modos de vivir, pueden modificar la situación presente. La necesidad de una reforma del pensamiento y la enseñanza es, así, incuestionable.

La propuesta morinista tiene la belleza ética y estética de enfrentar el esquema general de la dominación mediante una propuesta epistemológica abierta. Su doble apertura, como podemos leer en el primer tomo de El método ${ }^{6}$ consiste en abrirnos a la diversidad del conocimiento humano y a la diversidad de sus fuentes. ${ }^{7}$ No existe una propuesta más amplia y abierta a los contextos donde se desenvuelve la diversidad humana.

La apertura epistemológica a que convoca el "espíritu del valle" implica un replanteo muy radical de la cognición, que debe ser considerado a la hora de establecer diálogos con otras propuestas y conceptualizaciones. Si no se comparte la apertura epistemológica, el diálogo o es muy difícil, o se hace imposible. Este es un aspecto importante, pues en la demanda de reforma coinciden muchas tendencias sociales y políticas que están basadas en viejos presupuestos epistémicos cerrados, que perpetúan las relaciones de dominación con respecto a la naturaleza

34 y con respecto a otros seres humanos. El diálogo con esas tendencias es prácticamente imposible.

El pensamiento contemporáneo es diverso, crítico, rico en matices. Y cuando, a pesar de su diversidad, podemos encontrar puntos importantes de coincidencia en asuntos epistémicos fundamentales, entonces el diálogo de saberes se potencia. Es precisamente la situación que nos encontramos cuando tomamos juntas las propuestas de Morin, Potter y Freire. Son originales y diversas, parten de circunstancias específicas y están contextualizadas de manera que es imposible fundirlas en un conglomerado. Pero podemos hacerlas dialogar para replantearnos

${ }^{6}$ Véase, Edgar Morin, El método 1. La naturaleza de la naturaleza, 2001, Madrid, Cátedra, en específico su "Introducción general, El espíritu del valle", p. 19-39.

${ }^{7}$ Este mensaje fundamental que recoge "el espíritu del valle" se encuentra también en Los siete saberes... y su breve sección "A propósito de una bibliografía", donde reconoce que "cada país dispone de obras provenientes de su propia cultura", con lo que dirige la atención de quienes intenten la reforma a sus propias realidades actuales e históricas. Véase Edgar Morin, Los siete saberes necesarios para la educación del futuro, 1999, UNESCO, p. 60. 
problemas y buscarles soluciones. Al hacerlas dialogar, las posibilidades de una reforma profunda de la educación en Latinoamérica se incrementan.

Para los latinoamericanos este es un mensaje básico, pues los procesos de cambio social que han tenido lugar antes y que tienen lugar hoy en la región, han incluido siempre formas de cambio educativo. Esto significa que el cambio educativo forma parte de la agenda política del pasado y del presente, de manera que están a la orden del día los intereses sociales contrapuestos, las reflexiones filosóficas y pedagógicas, el cambio institucional y las demandas ciudadanas. No es algo nuevo y el riesgo de que se arrastre el cambio hacia la satisfacción de los intereses preconfigurados es enorme. Es urgente fundar el cambio en un nuevo pensamiento, en aras de evitar la reducción e instrumentalización para satisfacer únicamente los intereses tecnológicos, laborales y políticos inmediatos, y sobre todo, para evitar la reproducción de las relaciones de dominación, a la que no han escapado los procesos de cambio educativo más radicales.

Por otra parte, la aparición de nuevas fuerzas sociales -los movimientos sociales en el sentido más amplio, y la emergencia política de los pobladores originarios y su cultura-, han recolocado la problemática educativa y hacen urgente el diálogo de saberes. Hoy es más evidente que nunca antes que resulta imprescindible aprender de todos, y el aprendizaje incluye variables ecológicas y comportamentales con las cuales resultaría imposible dialogar si no se rompen las bases epistémicas y las lógicas de dominación que han sido heredadas desde la modernidad europea. Intentar un "diálogo" sin romper con las lógicas de dominación y los ideales clásicos de racionalidad conduciría únicamente a nuevos conflictos insolubles.

La apertura epistemológica de Morin y su orientación a la diversidad del conocimiento humano y sus fuentes convocan a incorporar a la reforma lo mejor del pensamiento educativo y político-social latinoamericano de todos los tiempos. Esto incluye, necesariamente, la apertura a nuestra diversidad comunitaria y cultural, pero incluye también el desarrollo de nuestra capacidad para pensar y elegir, dentro de nuestro acervo y del acervo del pensamiento universal. 
Son completamente insuficientes los intentos de reforma que se despliegan con fanfarria política y emoción gremial, que anuncian con tecnología y dispositivos electrónicos la llegada del futuro, mientras olvidan el presente de desigualdades y confinamiento de las mayorías para las que no parece existir ningún futuro.

Se necesita, entonces, un planteamiento de la reforma educativa, que desde la contextualización de la situación propia sea capaz de movernos hacia un futuro viable, construido desde nuestras propias circunstancias y nuestra inserción en el mundo. Esta contextualización debe llegar hasta las fuentes más profundas de nuestra identidad compartida, forjada en el período de lucha anticolonial, donde descuella como pensamiento colectivo original aquel electivismo con múltiple presencia en todo el subcontinente, que sin ser ecléctico, se reservaba el derecho de juzgar y ser selectivo con respecto a las ideas, el pensamiento y las transformaciones. Habrá que estudiar todavía las posibilidades que ofrece ese electivismo filosófico y metodológico para pensar los problemas contemporáneos, pero en él se encuentra, indudablemente, uno de los fundamentos de la creatividad ética, política y cognitiva que podremos desarrollar en la actualidad para formular problemas y encontrarles soluciones.

Y la reforma ha de basarse, además, en el más amplio diálogo de saberes. Un diálogo que ha de ser transdisciplinario por su naturaleza, lo que significa que involucrará directamente a los ciudadanos y las comunidades. La reforma entonces, ni podrá centrarse en los expertos, ni podrá confinarse a las instituciones educativas. En este amplio horizonte de un diálogo de saberes resulta imprescindible iniciar el diálogo entre las ideas fundacionales de Morin, Potter y Freire.

¿En qué coinciden estos autores? ¿Es posible un diálogo transdisciplinario a partir de ellos?

\section{Diálogo y aporte conjunto a una transformación profunda de la educación}

Al colocar a la cabeza de su "anti método" de pensamiento complejo el "espíritu del valle", Morin hace posible un eje aglutinador, dialogan- 
te con los contextos y la diversidad de las culturas. Su reclamo de una nueva actitud ante el conocimiento, la naturaleza y la humanidad, que no es dogmática, no es ecléctica, no es relativista, es propositiva, comprometida y responsable, lo acerca a los postulados electivos latinoamericanos. Por su parte Potter, al iniciar el camino de una bioética global heredera del legado de la ética ambiental fundada por Aldo Leopold, propuso inicialmente el tendido de un puente entre ciencias y humanidades, entre el presente y el futuro, entre las necesidades y responsabilidades de corto plazo y las de largo plazo, para más adelante, en su evolución intelectual, avanzar hacia el diálogo crítico con todas las éticas en la búsqueda de una nueva sabiduría: la sabiduría de cómo manejar el conocimiento. Un planteamiento sin duda medular para encauzar los derroteros de la reforma educativa. Mientras que Freire, al democratizar desde dentro el proceso pedagógico, al reconocer que "nadie enseña a nadie", sentó las bases para una pedagogía que coloca en el centro de su atención las relaciones de dominación. Así, los tres, aparentemente distantes en sus términos y conceptos, coinciden en replantear la educación y sus bases, y toman para ello como punto de partida la apertura crítica al resto de los saberes y las prácticas humanas. Las bases para un diálogo entre estas concepciones críticas de la educación y la enseñanza no pueden ser más sólidas.

Morin, Potter y Freire, originales y diferentes entre sí-por sus circunstancias específicas, sus conceptos y el discurso de sus propuestas-, tienen al menos ocho coincidencias epistémicas propias del ideal de racionalidad no clásico, que hacen posible el diálogo y la complementación: 8

1. Asumen la perspectiva del observador.

2. Critican el ideal de fragmentación y simplificación.

3. Reconocen la incertidumbre del conocimiento.

${ }^{8}$ Para la presente caracterización se han utilizado las obras de Edgar Morin ya mencionadas, así como los libros de Potter Bioética, puente al futuro, 1971, New Jersey, Prentice-Hall y Bioética global, 1988, Michigan State University Press; de la obra de Freire su Pedagogía del oprimido, 1969, Santiago de Chile, así como el volumen Lecciones de Paulo Freire, cruzando fronteras: experiencias que se completan, 2003, Buenos Aires, ClACsO. 
4. Demandan humildad cognoscitiva.

5. Asumen críticamente el conocimiento como dualidad ciencia-valor.

6. Demandan un cambio en el objeto de la ciencia para hacer posible la responsabilidad en la acción transformadora.

7. Proponen y exigen renovar desde sus raíces la educación, la enseñanza y el aprendizaje.

8. Reconocen las posibilidades epistémicas de todos los seres humanos, que pueden pensar el conocimiento e intentar conocer el conocimiento.

\section{Asumen la perspectiva del observador...}

La perspectiva del observador es uno de los rasgos distintivos de la racionalidad no clásica que estos autores comparten.

Morin lo plantea en la forma teórica más general, cuando centra la atención en la contextualización del conocimiento, a la vez que reconoce sus límites. El sujeto universal abstracto propio del discurso moderno es sustituido por un observador contextualizado en sus circunstancias biológicas, antropológicas, culturales y sociales. Una totalidad compleja que desaparece cuando separamos esos contextos, o cuando los yuxtaponemos.

Potter contextualiza el sujeto cognoscente que tiene hoy ante sí problemas que no estaban en el horizonte intelectual de sus predecesores. A la vez, reconoce el lugar del hombre común, del ciudadano y los científicos en la producción y el manejo del conocimiento y demanda constantemente el reconocimiento del contexto al cual pertenecen hoy: una sociedad que se preocupa más por el incremento exponencial del conocimiento y el progreso material que por alcanzar la sabiduría necesaria para manejar ese conocimiento.

Al igual que para Morin, para Potter no existe un sujeto privilegiado, que mire el mundo desde una perspectiva neutral y universal. Ambos reconocen el valor fundamental de un sujeto contextualizado, que produce conocimiento desde su circunstancia, biológica y socio cultural. Y lo distintivo de esa circunstancia contextual es, para Potter, el peligro que se cierne sobre la humanidad y que pone en riesgo su supervivencia a largo plazo. 
Por su parte, Freire asume presupuestos de segundo orden al reconocer el punto de vista específico del oprimido. Ni desventaja ni ventaja cognitiva, sino especificidad de un sujeto social, portador de una perspectiva epistémica que tiene valor en sí misma, y que es la base para el despliegue de sus potencialidades cognitivas. Por eso la educación tiene una dimensión eminentemente dialógica, donde nadie enseña a nadie.

En todos los casos se trata de presupuestos de segundo orden que se asumen para reconocer límites al conocimiento humano. Pero se trata de límites que no impiden el conocimiento, sino que lo hacen posible dentro de ciertos marcos, es decir, que lo habilitan.

\section{Critican el ideal de fragmentación y simplificación...}

Una crítica que Morin despliega ampliamente, desde una perspectiva teórica, al cuestionar los modos de organización de los conocimientos, la forma disciplinaria predominante en la actualidad y el extremo de la hiperespecialización, que reduce las posibilidades cognitivas de la humanidad. La reforma educativa debería corregir esta situación mediante un ejercicio sistemático de complejización o reconocimiento del desafío de la complejidad.

A su vez, Potter centró la atención en la fragmentación que expresa el distanciamiento y la separación entre ciencias y humanidades (el dilema de las dos culturas); entre el presente y el futuro (la falta de una ética y un compromiso con el futuro); la visión cortoplacista que no se preocupa por las consecuencias de largo plazo de nuestras acciones, y se centra exclusivamente en las consecuencias de corto plazo, lo que pone en riesgo la supervivencia de la especie humana.

Freire asumió, en este aspecto, un carácter radical, al señalar la separación entre el educador y el educando, la reproducción de los roles dominadores del receptor y el emisor en los procesos educativos, mediante la reproducción de una esquema donde alguien dotado de conocimientos y poder "enseña" a otro que en su pasividad reproductiva "aprende". Además, la superación de la fragmentación y la simplificación con respecto de los procesos educativos incluye su comprensión amplia de la educación dentro y fuera de los ambientes escolares, instituciona- 
les; el reconocimiento de la ausencia de fronteras para desarrollar los procesos educativos, también en el vínculo creador con los procesos de vida y la experiencia. La superación de la fragmentación se completa en la presentación de una pedagogía orientada a otros, en una comprensión solidaria del otro.

Una vez más, la crítica se torna planteamiento positivo de alternativas viables para un cambio superador de las fragmentaciones y las simplificaciones.

\section{Reconocen la incertidumbre del conocimiento...}

Quizá el aspecto más destacado en los comentarios de la obra de Morin, Potter y Freire sea éste de la incertidumbre del conocimiento. Exagerado en algunas interpretaciones, es indudablemente un punto medular para comprender el aporte de las ciencias contemporáneas y las necesidades de una nueva educación.

Morin reconoce la incertidumbre como aspecto cualitativo distintivo del conocimiento humano, y lo vincula a las problemáticas del error y la ilusión. El aprendizaje fundamental que nos falta, y del cual la reforma debería ocuparse, es el aprendizaje para manejar las incertidumbres.

40 Un giro total para invertir la situación actual, centrada en eliminar las incertidumbres, que serían sustituidas por certezas. En lugar de esta situación generalizada en la educación contemporánea, Morin propone un aprendizaje que haría posible el nuevo conocimiento como navegación entre archipiélagos de certeza.

Para Potter, se trata sobre todo de una incertidumbre de la especie humana ante el futuro y ante los imperativos de la sobrevivencia a largo plazo. Una incertidumbre irreductible, que emana de la diversidad humana y de los hechos probabilísticos, pero que no impide las acciones, sino que reclama acciones responsables. Ante la incertidumbre, la búsqueda de la sabiduría debería volverse sobre las bases biológicas del conocimiento humano y aprender también de la sabiduría biológica que nos muestran otras especies. No podemos superar o anular la incertidumbre sustituyéndola por certezas, pero podemos iniciarnos en una nueva sabiduría para aprender a manejar el conocimiento. 
Y en el mismo sentido, Freire reconoce el lado antropológico de la incertidumbre, se vuelve sobre el lado político de la educación y la replantea como educación emancipadora. No eliminará la incertidumbre, pero se colocará en el camino para manejarla mediante un aprendizaje permanente.

Extraordinaria coincidencia estratégica en reconocer la incertidumbre sin caer en la tentación de hacer de ello culto al inmovilismo y el pesimismo. Por el contrario, los tres coinciden en reconocer la posibilidad del conocimiento posible.

\section{Demandan humildad cognoscitiva...}

Y consecuentemente, la demanda de humildad cognoscitiva es coincidente.

En Morin deriva hacia la propuesta de una antropoética, profundamente política, comprometida con la incertidumbre, y humilde por su compromiso con la pertenencia humana a tres totalidades interpenetradas (individuo, sociedad, especie). Ésta es, a la vez, la humildad que democratiza y critica la ciencia sin conciencia y permite el diálogo entre las formas más diversas del conocimiento humano.

Para Potter, se trata de una humildad que debe exigirse a la ciencia. Humildad científica, que haga posible la formulación de una pregunta fundamental: “¿podría estar equivocado?” La ciencia capaz de hacerse esta pregunta estaría en el camino de la humildad humana, necesaria para reconocer nuestra pertenencia a la naturaleza.

En Freire vuelve a ser, nítidamente, humildad antropológica y ciudadana. Es la humildad que emana de reconocer que los humanos tenemos un carácter inacabado en tanto personas. Lo que hace posible la acción humana y la acción educativa dentro de ella. Seríamos así, programados por una educación social, pero no estaríamos completamente determinados por ella.

Los tres reconocen la humildad como condición para comprendernos como totalidades, inacabadas, transformables, educables. 


\section{Asumen críticamente el conocimiento como dualidad ciencia-valor...}

Es Morin quien plantea el conocimiento como una construcción humana que emana de un cogito, que tiene su antecedente en el computo viviente. Sin menosprecio de las bases biológicas del conocer, es la comprensión de la producción de conocimiento desde nuestras propias circunstancias humanas. Así, se reconoce el vínculo del conocimiento y los valores en una trama donde se mezclan y dialogan la verdad y el error, la producción de imaginarios y la multiplicidad de un ser que es sapiens, demens, faber, ludens... complexus.

En Potter deviene imperativo ético y gnoseológico, pues implica un cambio en el objeto de la ciencia, que debería ocuparse no sólo de decirnos cómo es el mundo, sino de explicarnos cómo utilizar el conocimiento que ella producen para beneficio de la humanidad.

Y en Freire es un conocimiento de qué y para quién, inseparable de las circunstancias de una producción colectiva, social e histórica, pero que no tienen atributo de eternidad. Pueden ser superadas mediante el desenvolvimiento de acciones sociales, cuyo primer paso consiste en pensar esa relación valor-conocimiento. Y aquí vuelve a ser el diálogo aquel recurso y dispositivo posibilitador del inicio de la transformación.

6. Demandan un cambio en el objeto de la ciencia para hacer posible la responsabilidad en la acción transformadora...

Los tres coinciden en su crítica al estado de la ciencia y su mirada al mundo. En Morin, como demanda y pronóstico de la llegada de una ciencia nueva, que se abra al diálogo inter y transdisciplinario, que supere la segmentación y la separación, que atienda al desafío de la complejidad. En Potter, como exigencia a la ciencia para que sea humilde y se pregunte por el uso del conocimiento, para que incorpore la pregunta ética en su objeto de estudio y llegue con ello a ser responsable. Y ésta sería una ciencia nueva, al igual que lo es la pedagogía responsable que nos propone Freire: una que deje de ser ejercicio y justificación de la educación bancaria, que problematice y sea crítica con 
respecto al mundo social, creadora con ello de nuevas visiones sobre la realidad -perspectiva crítica donde recurre una vez más a presupuestos de segundo orden. Una pedagogía capaz de construir/reconstruir las relaciones entre lo pedagógico, lo político, lo ético y lo estético.

7. Proponen y exigen renovar desde sus raíces la educación, la enseñanza y el aprendizaje...

Una reforma del pensamiento y la enseñanza que permita poner la cabeza en su lugar. Una educación bioética, intercultural y profunda, que amplíe el círculo de la moralidad para incluir a la naturaleza en nuestra comprensión de la responsabilidad. Una educación nueva, que sea autoeducación, dialogante, crítica, habilitadora de las potencialidades propias, contextualizada. Liberadora, en sentido ético y político, pues evitará la subordinación y el acomodo de los sujetos a los sistemas injustos y opresores.

8. Reconocen las posibilidades epistémicas de todos los seres humanos, que pueden pensar el conocimiento e intentar conocer el conocimiento...

Punto coincidente con el primero, pues la postura de segundo orden renuncia al sujeto universal y con ello al sujeto privilegiado.

En Morin, se enlaza con el análisis de los niveles de la enseñanza escolarizada, y de las aportaciones de la diversidad cultural. Con la superación de la sociedad que ha delegado el poder del conocimiento en los expertos y que se basaría, entonces, en una nueva democracia cognoscitiva: en la devolución del poder del conocimiento a los ciudadanos. $\mathrm{Su}$ mensaje explicito: devolver el eros educativo.

En Potter, con el reconocimiento de las posibilidades del hombre común y la interculturalidad, para llegar a un mensaje crítico y ecuménico en su bioética global. Su mensaje explícito: que el individuo es parte de una comunidad de partes interdependientes.

Y en Freire, en la transformación de la pedagogía en un ejercicio dialógico que supera el método y la dominación propia de la educación banca- 
ria, que es encuentro de interlocutores y está destinada a la creación de un mundo en el que sea menos difícil amar.

Una reforma profunda, por tanto, no es sólo deseable y necesaria, es posible. Demanda de los educadores actuar en el aula, en la organización educativa, en la sociedad. Morin, Potter y Freire, en sus coincidencias, nos aportan las bases mínimas para un diálogo fructífero que la haga realidad. 